\title{
Factors Associated With The Mental Health of Back-To-Wuhan College Students Based On Quantile Regression Model During The COVID-19 Period
}

\author{
Qian Wu \\ Huazhong University of Science and Technology \\ Lijun Zhuo \\ Huazhong University of Science and Technology \\ Hao Li \\ Huazhong University of Science and Technology \\ Ling Zheng \\ Huazhong University of Science and Technology \\ Guoqing Ma \\ Huazhong University of Science and Technology \\ Hongbing Tao ( $\sim$ hhbtao@hust.edu.cn) \\ Huazhong University of Science and Technology
}

\section{Research Article}

Keywords: COVID-19, mental health, college students, quantile regression analysis, discrimination

Posted Date: September 14th, 2021

DOI: https://doi.org/10.21203/rs.3.rs-778511/v1

License: (c) (i) This work is licensed under a Creative Commons Attribution 4.0 International License. Read Full License 


\section{Abstract \\ Background}

The COVID-19 pandemic has been spreading rapidly in China and other countries since December 2019, which has increased the risk of infection, and brought the unbearable huge psychological pressure on people.

\section{Methods}

A cross-sectional questionnaire survey was conducted from 31 August 2020, to 14 September 2020 by convenience sampling on the back-to-Wuhan college students, which included the Generalized Anxiety Disorder Scale (GAD-7), Patient Health Questionnaire-9 (PHQ-9), the Insomnia Severity Index-7 (ISI-7), and the revised Impact of Event Scale (IES-R) scales and the basic demographic characteristics.

\section{Results}

The results from 1017 participants suggested that $44 \%, 47.5 \%, 37.7 \%, 57.7 \%$ were the prevalence rates of the anxiety, depression, insomnia, and distress respectively. Moreover, quantile regression analysis was used to identify the factors related to the mental health variables of the back-to-Wuhan college students during the COVID-19 period.

\section{Conclusion}

The finding showed that the respondents who were near graduation, discriminated owing to the experience in Wuhan, and worried about the future trend of COVID-19 had a higher risk of becoming negative psychologic status, especially the bottom and median quantile, and might require more psycho-social interventions or support.

\section{Background}

The novel Coronavirus 2019(COVID-19) which was first reported in Wuhan, Hubei province, China in late December 2019 could be transmitted by respiratory tract and aerosol, and have had a huge impact on the world[1]. Owing to the quarantine measures lasted for more than two months, the number of new confirmed cases and suspected cases in China have gradually reduced, and the pandemic in China was under control [2]. Unfortunately, it wasn't the case in the other countries. As of Oct 31, 2020, the World Health Organization announced that the number of cumulative confirmed cases worldwide is nearly 460.2 million, and the cumulative dead patients are 1.2 million. Previous studies have showed that large-scale, unexpected public health events such as the severe acute respiratory syndrome (SARS) epidemic in China in 2003[3, 4] and the Middle East respiratory syndrome coronavirus in 2014[5, 6], not only threatened people's physical health, but also caused serious harm to people's psychology[7], and this psychological impact may last for a long time[8, 9].

As a worldwide public health emergency, the spread of the COVID-19 had a certain, negative effect on people' mental health, especially on some key populations[10]. At present, there have been many pieces of researches on public mental health, including medical staff, patients, children, the elderly during the COVID-19 outbreak. The research of a multi-center online survey on 1563 medical staff suggested that the detection rates of depression, anxiety, insomnia and stress symptoms were as high as $50.7 \%, 44.7 \%, 36.1 \%$ and $73.4 \%[11]$.Chen et al[12] surveyed of 12,759 medical staff, which indicated that the psychological abnormality detection rate of medical staff was $36.1 \%$, higher than the public psychological abnormality examination rate during the COVID-19 epidemic[13]. Similarly, the COVID-19 had serious repercussions for the mental health of the discharged patients, whose proportion of moderate to severe anxiety was $10.4 \%$, severe depression was $19 \%[14]$. The elderly also suffered from serious mental health problems, who were hard to get psychological assistance online. [15].

During the SARS epidemic, college students who were not contaminated with the disease had SARS-related psychological problems with sex and demographic differences[16]. In the period of hemagglutinin type-1 neuraminidase type-1 influenza virus (H1N1), university students in Guangzhou, China had mental distress caused by fear of $\mathrm{H} 1 \mathrm{~N} 1$, and some preventive measures, including mental health education and promotion were warranted to alleviate the mental distress[17]. Since the COVID-19 outbreak was first reported, considerable attention has been drawn to physical and psychological health among college students, especially in Wuhan, the epicenter of the COVID-19 pandemic. Additionally, students regarded as carriers of the virus were discriminated against causing the stress, anxiety, and fear problems [18]. A large number of universities have postponed the beginning date of new term and adopted the Elearning mode[19]. While preliminary evidence illustrated that the home-quarantined college students worried about the COVID-19 were supposed to affect their mental health. $24.9 \%$ of 7,143 college students in home isolation suffered from mild anxiety and Above[20]. Among the 3881 undergraduates surveyed, the incidence of anxiety and depression were $26.60 \%$ and $21.16 \%$, respectively [21], higher than the average prevalence rate for college students in the nonpandemic period [22]. Previous research suggested that there would be a long-term negative impact on people's psychological health in a public health crisis. Hence, the impact factors should be explored actively[23].

The implementation of off-line classroom teaching in American universities caused cluster of infection after the students returned to the university, approximately a total of 150 students were diagnosed during half a month. In September 2020, a large number of college students returned to school in Wuhan. To reduce the risk of infection, closed management measures, including students "unnecessarily not going out", wearing masks and maintaining social distance were put into effect (Ministry of Education of the People's Republic of China,2020), which might influence the study life and psychological wellbeing of back-to-Wuhan college students. Previous research showed that there were more suicidal behaviors among college students with post-traumatic 
stress and poor mental health, especially for female college students[24]. Measuring and evaluating the mental health of college students are conducive to monitor mental health diseases and behavioral problems, and being able to predict and intervene in behavior changes (Greene, 2005). Therefore, it is necessary to pay attention to the mental health of back-to-Wuhan college students, identify key impact factors and implement efficient interventions as soon as possible[25].

For universities, how to guide the students to deal with the public health emergencies, control their feelings and avoid sinking into negative emotions have become an issue of far greater momentousness and urgency to solve. Thus, after the COVID19 epidemic, this current research surveyed mental health and influence factors of back-to-Wuhan college students makes sense.

The aims of this study are:(i) to analyze the mental health of back-to-Wuhan college students in Wuhan during the post-COVID-19 epidemic period; (ii) to find the key impact factors of mental health variable and then to provide a certain basis of preventing and intervening the mental health of college students measures.

\section{Methods}

\section{Study Design}

This research is a crossed-sectional survey, using an online questionnaire to measure mental health variables, including anxiety, depression, insomnia, and distress of back-to-Wuhan college students by the 'Questionnaire Star Application'. This research met ethical protocols (No: IORG0003571).

Convenience sampling was conducted to collect data from 31 August 2020, to 14 September 2020 in Wuhan. The purpose and content of this survey had been explained to each respondent, and the respondent's informed verbal consent had been obtained. Each questionnaire was filled out anonymously.

\section{Participants}

The questionnaires of participants were mostly completed online from different universities on account of the closed management. The inclusion criteria were:(i) college students covering undergraduate, master and doctoral candidate, who studied in Wuhan before the COVID-19 outbreak and currently; (ii) 18 years old and above. The samples missing the key items of questionnaire were excluded.

The formula of the target participant sample size is following $N=Z_{a}{ }^{2} P(1-P) / \delta^{2},\left(a=0.05, Z_{a}=1.96, P\right.$ means the positive rate of mental health problem), and the absolute allowable error of ratio estimate $\delta$ was 0.05 . The positive rate is $38.4 \%$ at internalizing disorder especially depression and anxiety disorder among college students in the previous study[26]. For the reduce of sampling error, we expanded the sample size by $50 \%$ with the goal of participants at least 546 completed questionnaires. A total of 1,332 back-to-Wuhan college students were surveyed, 192 people refused to participate, and 1,017 valid samples were included, with an effectivity rate of $76.35 \%$.

\section{Measures}

The general questionnaire mainly included two parts. The first part was sociodemographic information, such as age, gender, department category of the university, hometown, years from graduation, whether you have been discriminated against because of studying in Wuhan, and whether COVID-19 rebound again in China.

The second part was mental health variables, including anxiety, depression, insomnia, and distress, measured by the Generalized Anxiety Disorder Scale (GAD7) ranging 0-21, the Patient Health Questionnaire (PHQ-9) ranging 0-27, the Insomnia Severity Index (ISI-7) ranging 0-28, and the Impact of Event ScaleRevised (IES-R) respectively. These scales had good reliability and validity in previous studies [2, 27-29]. The scores of these scales are classified as follows: GAD-7, normal (0-4), mild (5-9), moderate (10-13), moderate to severe (14-18), and severe (19-21);PHQ-9, nomal (0-4), mild (5-9), moderate to severe (10-14), and severe (20-27); ISI-7, normal (0-7), mild (8-14), moderate (15-21), severe (22-28);IES-R, normal (0-7), mild (8-14), moderate (15-21) and severe (22-28). The Cronbach's alpha coefficients of the Chinese versions of PHQ-9, GAD-7, ISI-7 and IES-7 were 0.929,0.918, 0.903 and 0.899 , respectively. Therefore, the internal consistency was excellent in the current study.

\section{Statistical Analysis}

Stata statistical software version 15.0 (StataCorp LLC, Texas, USA) was used to analyze the data. First, sociodemographic characteristics were illustrated by quantity and frequency. Normality distributions test was used for dependent variables. Pearson's correlations were performed to test the correlation among the influence factor and mental health variables. Secondly, the Kruskal-Wallis test was applied for the difference comparison among groups, in which the prevalence rate of anxiety (GAD7 $\geq 5$ points), depression (PHQ $9 \geq 5$ points), insomnia (ISI $7 \geq 8$ points), distress (IES $7 \geq 8$ points) could be evaluated, respectively. Finally, quantile regression was used to explore regression relationship of mental health variables and sociodemographic characteristics. Moreover, considering the distribution characteristics of the dependent variables, the $P_{25}, P_{50}, P_{75}$ conditional quantile points were selected as representatives to describe the quantile regression analysis results. The better group (represented by $\mathrm{P}_{25}$ quantile points), general group (represented by $\mathrm{P}_{50}$ quantile points), and poor group (represented by $\mathrm{P}_{75}$ quantile points) of each dependent variable showed the sociodemographic characteristics related to anxiety, depression, insomnia, and distress.

\section{Results}

\section{Sociodemographic Characteristics}


As is revealed in Table 1, a total of 1017 back-to-Wuhan college students participated in the questionnaire survey. Among them, 475 (46.7\%) are males, and more than $92.8 \%$ participants are between $18-25$ years old. The number and proportion of undergraduates, postgraduates, doctors are 490 (48.2\%), 447 (44\%) ,80 (7.9\%), respectively. $363(35.7 \%)$ are medical students. There are $684(67.2 \%)$ students with less than two years left before graduation. Only 41 (4\% ) of the university students surveyed are from Wuhan, 283 (27.8\%) students are from Hubei Province except for Wuhan, and 693 (68.1\%) students from other provinces. Most students [604 (59.4\%)] have been discriminated against because of their experience in Wuhan. 258 (25.4\%) respondents are optimistic about the COVID-2019 epidemic, 322 (31.7\%) respondents believe that the epidemic might rebound.

Table 1

The sociodemographic characteristics of participants

\begin{tabular}{|c|c|c|}
\hline & Total & $\%$ \\
\hline Total & 1017 & 100 \\
\hline \multicolumn{3}{|l|}{ Sex } \\
\hline Male & 475 & 46.7 \\
\hline Female & 542 & 53.3 \\
\hline \multicolumn{3}{|l|}{ Age } \\
\hline $18-21$ & 431 & 42.4 \\
\hline $22-25$ & 513 & 50.4 \\
\hline $26-29$ & 63 & 6.2 \\
\hline$\geq 30$ & 10 & 1 \\
\hline \multicolumn{3}{|l|}{ Highest Education level } \\
\hline Undergraduate student & 490 & 48.2 \\
\hline Master student & 447 & 44 \\
\hline PHD student or above & 80 & 7.9 \\
\hline \multicolumn{3}{|l|}{ Department category of the university } \\
\hline Department of Medicine-related & 363 & 35.7 \\
\hline Department of Non-Medicine-related & 654 & 64.3 \\
\hline \multicolumn{3}{|l|}{ Years from graduation } \\
\hline Within 1 year & 348 & 34.2 \\
\hline Within 2 year & 336 & 33 \\
\hline Within 3 year & 242 & 23.8 \\
\hline 4 years and above & 91 & 8.9 \\
\hline \multicolumn{3}{|l|}{ Hometown } \\
\hline Wuhan & 41 & 4 \\
\hline Hubei except for Wuhan & 283 & 27.8 \\
\hline Other provinces & 693 & 68 \\
\hline \multicolumn{3}{|l|}{ Whether Be discriminated } \\
\hline Yes & 413 & 40.6 \\
\hline No & 604 & 59.4 \\
\hline \multicolumn{3}{|l|}{ COVID-19 be rebounding again } \\
\hline Yes & 322 & 31.7 \\
\hline No & 258 & 25.4 \\
\hline Uncertain & 437 & 43 \\
\hline
\end{tabular}

\section{The Distribution And Correlation Among Variables}


Table 2 presents the score distributions of GAD-7, PHQ-9, ISI-7, IES-R scales. From the skewness, kurtosis and extreme value distribution ratio, the scores of each dimension don't conform to the normal distribution $(P<0.01)$.

Table 3 provides the correlations between the sociodemographic characteristics and the mental health variables, respectively, and reflects the positive and negative correlations significantly in detail.

Table 2

The distribution characteristics of mental health variables.

\begin{tabular}{lllllllllr} 
& Mean & Standard deviation & Median & Mode & Skewness & Kurtosis & Normal-proportion & Severe- proportion & Normality \\
\hline GAD-7 & 4.36 & 4.3 & 4 & 0 & 1.04 & 0.88 & 0.56 & 0.05 & $<0.01$ \\
PHQ-7 & 5.18 & 5.18 & 4 & 0 & 1.12 & 1.1 & 0.53 & 0.06 & 0.11 \\
ISI-7 & 6.76 & 5.49 & 6 & 0 & 0.87 & 0.31 & 0.62 & $<01$ \\
IES-R & 8.75 & 5.01 & 8 & 8 & 0.39 & 0.11 & 0.42 & $<.13$ & $<0.01$ \\
\hline
\end{tabular}

Note.GAD-7 = 7-item General Anxiety Disorder Scale, PHQ-9 = 9-item Patient Health Questionnaire(depression), ISI-7 = 7-item Insomnia Severity Index Scale, IES-R $=$ the Impact of Event Scale-Revised(distress). ${ }^{\star *} \mathrm{P}<0.01 * \mathrm{P}<0.05$.

Table 3

Pearson's correlations among variables.

\begin{tabular}{|c|c|c|c|c|c|c|c|c|}
\hline Variable & 1 & 2 & 3 & 4 & 5 & 6 & 7 & 8 \\
\hline 1.Sex & 1 & & & & & & & \\
\hline 2.Age & $0.10^{\star \star}$ & 1 & & & & & & \\
\hline 3.Highest Education level & $0.08^{*}$ & $0.76^{\star \star}$ & 1 & & & & & \\
\hline 4.Department category of the university & $-0.19^{\star *}$ & $-0.17^{\star \star}$ & $-0.10^{* *}$ & 1 & & & & \\
\hline 5.Years from graduation & -0.04 & $-0.20^{\star *}$ & -0.002 & $-0.09^{\star *}$ & 1 & & & \\
\hline 6.Hometown & -0.03 & -0.03 & $<0.001$ & 0.03 & $0.07^{\star}$ & 1 & & \\
\hline 7.Whether be discriminated & -0.04 & $-0.11^{\star \star}$ & $-0.10^{\star *}$ & 0.06 & 0.05 & $-0.22^{\star \star}$ & 1 & \\
\hline 8.COVID-19 be rebounding again & $0.13^{\star \star}$ & -0.04 & -0.03 & 0.04 & -0.03 & $0.06^{*}$ & 0.06 & 1 \\
\hline 9.GAD-7 & 0.01 & 0.04 & 0.04 & -0.03 & $-0.07^{\star}$ & 0.02 & $-0.09^{\star \star}$ & $-0.10^{\star *}$ \\
\hline 10.PHQ-9 & 0.05 & $0.10^{\star \star}$ & 0.05 & -0.02 & $-0.08^{\star \star}$ & -0.01 & $-0.09^{\star \star}$ & $-0.07^{*}$ \\
\hline 11.ISI-7 & 0.04 & $0.18^{\star \star}$ & $0.16^{* *}$ & -0.02 & $-0.07^{*}$ & -0.01 & $-0.10^{\star \star}$ & $-0.08^{*}$ \\
\hline 12.IES-R & -0.002 & $0.09^{\star *}$ & 0.05 & $-0.06^{*}$ & $-0.12^{\star \star}$ & -0.004 & $-0.17^{\star \star}$ & $-0.08^{* *}$ \\
\hline
\end{tabular}

Note.GAD-7 = 7-item General Anxiety Disorder Scale, PHQ-9 = 9-item Patient Health Questionnaire(depression), ISI-7 = 7-item Insomnia Severity Index Scale, IES-R $=$ the Impact of Event Scale-Revised(distress). ${ }^{* * P}<0.01 * \mathrm{P}<0.05$.

\section{The Severity Of Measurements And Associated Factors}

As shown in Table 4, there is quite a large proportion of respondents with symptom of anxiety [447 (44\%)], depression [483 (47.5\%)], insomnia [383 (37.7\%)], and distress [587 (57.7\%)]. Kruskal-Wallis test demonstrates that the prevalence rates of anxiety, insomnia and distress varies among different ages, levels of education, whether the colleges were discriminated owing to the experience in Wuhan $(P<0.05)$. Also, the opposite attitude to the future trend of the COVID2019 epidemic has led to the different infection rates of anxiety and distress $(P<0.05)$. For whom were discriminated due to the experience in Wuhan, they are easily to develop the psychological symptoms of depression $(P<0.05)$. Simultaneously, whether the participants suffering from the distress are affected by sex, year from graduation, and the attitude to the future trend of the COVID-2019 $(P<0.05)$.

In Table 5, the results of quantile regression suggest that the influence coefficient of various factors on the mental health variables of college students in different quantiles has changed significantly. Further, age, years from graduation, being discriminated against owing to the experience in Wuhan, and the attitude on the future of COVID-2019 are negatively associated to the mental health scores, while the education level is positively related to it.

The uncertainty on the future trend of COVID-2019, and being discriminated against owing to the experience in Wuhan are associated with an increase of anxiety and distress, especially for those in lower quantile. The column (1) of Table 4 reveals the effect of education level wildly across anxiety, 1.64 in the 25 th quantile changing to 2.54 in the 50th quantile, and was merely significant at the lower quantiles. 
Analogously, in column (2) of Table 4, the heavier the scientific research tasks, the more depression on the participants, changing from 2.04 in the 25 th quantile to 2.84 in the 75 th quantile. Columns 3-4 of Table 4 presents that those were both significant and negative at 25th, 50th, and 75 th quantiles and the college students in graduation grade developed insomnia (25th $=-2.32,75$ th $=-3.33)$ and distress $(25$ th $=-1.74,75$ th $=-2.16)$. 
Table 4

The prevalence rates under different sociodemographic characteristics

\begin{tabular}{|c|c|c|c|c|c|c|c|c|c|c|c|}
\hline & \multicolumn{3}{|l|}{ GAD-7 } & \multicolumn{3}{|l|}{ PHQ-9 } & \multicolumn{3}{|l|}{ ISI-7 } & \multicolumn{2}{|l|}{ IES-R } \\
\hline & $<5$ & $\geq 5$ & V- & $<5$ & $\geq 5$ & p- & $<8$ & $\geq 8$ & p-Value & $<8$ & $\geq 8$ \\
\hline Total & $570(56)$ & $447(44)$ & & $534(52.5)$ & $483(47.5)$ & & $634(62.3)$ & $383(37.7)$ & & $430(42.3)$ & $587(57.7)$ \\
\hline \multicolumn{12}{|l|}{ Sex } \\
\hline Male & $270(47.4)$ & $205(45.9)$ & \multirow[t]{2}{*}{0.633} & $265(49.6)$ & $210(43.5)$ & \multirow[t]{2}{*}{0.050} & $308(48.6)$ & $167(43.6)$ & \multirow[t]{2}{*}{0.123} & 199(46.3) & $276(47)$ \\
\hline Female & $300(52.6)$ & $242(54.1)$ & & $269(50.4)$ & $273(56.5)$ & & $326(51.4)$ & $216(56.4)$ & & 231(53.7) & $311(53)$ \\
\hline \multicolumn{12}{|l|}{ Age } \\
\hline $18-21$ & $262(46)$ & $169(37.8)$ & \multirow[t]{4}{*}{$0.024^{*}$} & $245(45.9)$ & $186(38.5)$ & \multirow[t]{4}{*}{$0.018^{*}$} & $304(47.9)$ & 127(33.2) & \multirow[t]{4}{*}{$<0.001^{\star *}$} & $205(47.7)$ & $226(38.5)$ \\
\hline $22-25$ & $266(46.7)$ & $247(55.3)$ & & $254(47.6)$ & $259(53.6)$ & & $297(46.8)$ & $216(56.4)$ & & $199(46.3)$ & $314(53.5)$ \\
\hline $26-29$ & $37(6.5)$ & $26(5.8)$ & & $31(5.8)$ & $32(6.6)$ & & $29(4.6)$ & $34(8.9)$ & & $23(5.3)$ & $40(6.8)$ \\
\hline$\geq 30$ & $5(0.9)$ & $5(1.1)$ & & $4(0.7)$ & $6(1.2)$ & & $4(0.6)$ & $6(1.6)$ & & $3(0.7)$ & $7(1.2)$ \\
\hline \multicolumn{12}{|l|}{$\begin{array}{l}\text { Education } \\
\text { level }\end{array}$} \\
\hline $\begin{array}{l}\text { Undergraduate } \\
\text { student }\end{array}$ & 291(51.1) & 199(44.5) & \multirow[t]{3}{*}{$0.043^{*}$} & $275(51.5)$ & $215(44.5)$ & \multirow[t]{3}{*}{0.064} & $337(53.2)$ & 153(39.9) & \multirow[t]{3}{*}{$<0.001^{* *}$} & 223(51.9) & $267(45.4)$ \\
\hline $\begin{array}{l}\text { Master } \\
\text { student }\end{array}$ & $237(41.6)$ & $210(47)$ & & $215(40.3)$ & $232(48)$ & & $255(40.2)$ & 192(50.1) & & $175(40.7)$ & $272(46.3)$ \\
\hline $\begin{array}{l}\text { PHD student } \\
\text { or above }\end{array}$ & $42(7.4)$ & $38(8.5)$ & & $44(8.2)$ & $36(7.5)$ & & $42(6.6)$ & $38(9.9)$ & & $32(7.4)$ & $48(8.2)$ \\
\hline \multicolumn{12}{|l|}{$\begin{array}{l}\text { Department } \\
\text { category of } \\
\text { the university }\end{array}$} \\
\hline $\begin{array}{l}\text { Department of } \\
\text { Medicine- } \\
\text { related }\end{array}$ & $195(34.2)$ & $168(46.3)$ & \multirow[t]{2}{*}{0.265} & $183(34.3)$ & $180(37.3)$ & \multirow[t]{2}{*}{0.319} & 228(36) & $135(35.2)$ & \multirow[t]{2}{*}{0.818} & 139(32.3) & $224(38.2)$ \\
\hline $\begin{array}{l}\text { Department of } \\
\text { Non-Medicine- } \\
\text { related }\end{array}$ & $375(65.8)$ & $279(62.4)$ & & $351(65.7)$ & $303(62.7)$ & & $406(64)$ & $248(37.9)$ & & 291(67.7) & $363(61.8)$ \\
\hline \multicolumn{12}{|l|}{$\begin{array}{l}\text { Years from } \\
\text { graduation }\end{array}$} \\
\hline Within 1 year & $186(32.6)$ & $162(36.2)$ & \multirow[t]{4}{*}{0.123} & 171(32) & $177(36.6)$ & \multirow[t]{4}{*}{0.053} & 205(32.3) & 143(37.3) & \multirow[t]{4}{*}{0.092} & $124(28.8)$ & $224(38.2)$ \\
\hline Within 2 year & $185(32.5)$ & 151(33.8) & & $174(32.6)$ & 162(33.5) & & 211(33.3) & $125(32.6)$ & & 143(33.3) & 193(32.9) \\
\hline Within 3 year & 147(25.8) & $95(21.3)$ & & 138(25.8) & 104(21.5) & & $160(25.2)$ & $82(21.4)$ & & $120(27.9)$ & $122(20.8)$ \\
\hline $\begin{array}{l}4 \text { years and } \\
\text { above }\end{array}$ & $52(9.1)$ & $39(8.7)$ & & $51(9.6)$ & $40(8.3)$ & & $58(9.1)$ & $33(8.6)$ & & $43(10)$ & $48(8.2)$ \\
\hline \multicolumn{12}{|l|}{ Hometown } \\
\hline Wuhan & 19(3.3) & $22(4.9)$ & \multirow[t]{3}{*}{0.361} & $18(3.4)$ & $23(4.8)$ & \multirow[t]{3}{*}{0.323} & $28(4.4)$ & $13(3.4)$ & 0.982 & $18(4.2)$ & 23(3.9) \\
\hline $\begin{array}{l}\text { Hubei except } \\
\text { Wuhan }\end{array}$ & 171(30) & $112(25.1)$ & & 161(30.1) & $122(25.3)$ & & $173(27.3)$ & $110(28.7)$ & & $116(27)$ & $167(28.4)$ \\
\hline $\begin{array}{l}\text { Other } \\
\text { provinces }\end{array}$ & $380(66.7)$ & $313(70)$ & & $355(66.5)$ & $338(79)$ & & $433(68.3)$ & $260(67.9)$ & & $296(68.8)$ & $397(67.6)$ \\
\hline $\begin{array}{l}\text { Whether Be } \\
\text { discriminated }\end{array}$ & & & & & & & & & & & \\
\hline Yes & 216(37.9) & 197(44.1) & $0.047^{*}$ & 198(37.1) & $215(44.5)$ & $0.016^{\star}$ & $233(36.8)$ & $180(47)$ & $0.001^{\star \star}$ & 134(31.2) & $279(47.5)$ \\
\hline No & $354(62.1)$ & $250(55.9)$ & & $336(62.9)$ & $268(55.5)$ & & $401(63.2)$ & 203(53) & & $296(68.8)$ & $308(52.5)$ \\
\hline $\begin{array}{l}\text { The COVID-19 } \\
\text { whether } \\
\text { rebound again } \\
\text { in China }\end{array}$ & & & & & & & & & & & \\
\hline Yes & $157(27.5)$ & $165(36.9)$ & $0.027^{*}$ & $154(28.8)$ & 168(34.8) & 0.261 & $190(30)$ & 132(34.5) & 0.175 & $110(25.6)$ & $212(36.1)$ \\
\hline
\end{tabular}

Note.GAD-7 = 7-item General Anxiety Disorder Scale, PHQ-9 = 9-item Patient Health Questionnaire(depression), ISI-7 = 7-item Insomnia Severity Index Scale, IE! Impact of Event Scale-Revised(distress). ${ }^{\star *} P<0.01 * P<0.05$. 


\begin{tabular}{|c|c|c|c|c|c|c|c|c|c|c|c|}
\hline & GAD-7 & & & PHQ-9 & & & ISI-7 & & & IES-R & \\
\hline & $<5$ & $\geq 5$ & $\begin{array}{l}\mathrm{p}- \\
\text { Value }\end{array}$ & $<5$ & $\geq 5$ & $\begin{array}{l}\mathrm{p}- \\
\text { Value }\end{array}$ & $<8$ & $\geq 8$ & p-Value & $<8$ & $\geq 8$ \\
\hline No & $160(28.1)$ & 98(21.9) & & 149(27.9) & 109(22.6) & & 164(25.9) & $94(24.5)$ & & $128(29.8)$ & $130(22.1)$ \\
\hline Uncertain & $253(44.4)$ & $184(41.2)$ & & $231(43.3)$ & $206(42.7)$ & & $280(44.2)$ & 157(41) & & 192(44.7) & $245(41.7)$ \\
\hline
\end{tabular}

Note.GAD-7 = 7-item General Anxiety Disorder Scale, PHQ-9 = 9-item Patient Health Questionnaire(depression), ISI-7 = 7-item Insomnia Severity Index Scale, IE! Impact of Event Scale-Revised(distress). ${ }^{* *} P<0.01 * P<0.05$

Table 5

Different quantiles analysis of mental health and associated factors

\begin{tabular}{|c|c|c|c|c|c|c|c|c|c|c|c|}
\hline & \multicolumn{3}{|l|}{ (1) GAD-7 } & \multicolumn{3}{|c|}{ (2) PHQ-9 } & \multicolumn{3}{|l|}{ (3) ISI-7 } & \multicolumn{2}{|l|}{ (4) IES-R } \\
\hline & $P_{25}$ & $P_{50}$ & $P_{75}$ & $P_{25}$ & $P_{50}$ & $P_{75}$ & $P_{25}$ & $P_{50}$ & $P_{75}$ & $P_{25}$ & $P_{50}$ \\
\hline \multirow[t]{2}{*}{ Sex } & 0.0909 & 0.2478 & -0.327 & -0.765 & 0.2500 & 0.5714 & 0.2500 & -0.3333 & -0.6667 & 0.1537 & -0.3333 \\
\hline & (0.35) & (0.53) & $(-0.73)$ & $(-0.57)$ & (0.55) & $(0.87)$ & (0.59) & $(-0.95)$ & $(-1.68)$ & (0.59) & $(0.63)$ \\
\hline \multirow[t]{2}{*}{ Age } & -1.0000 & $-2.2500^{*}$ & -0.5230 & -0.0833 & 1.0000 & 2.0000 & 0.0833 & 0.6667 & 0.3333 & 0.1111 & -0.3333 \\
\hline & $(-1.85)$ & $(-2.34)$ & $(-0.71)$ & $(-0.09)$ & $(1.06)$ & (1.48) & $(0.09)$ & $(0.92)$ & $(0.41)$ & $(0.14)$ & $(-0.31)$ \\
\hline \multirow{2}{*}{$\begin{array}{l}\text { Highest } \\
\text { Education } \\
\text { level }\end{array}$} & $0.3636^{\star}$ & $1.2700^{*}$ & 0.2500 & $0.7500 *$ & $1.0000^{\star *}$ & $1.5714^{\star \star}$ & 0.3333 & -0.2765 & -0.4160 & 0.4444 & 0.3333 \\
\hline & (1.64) & (2.54) & $(0.86)$ & (2.04) & (2.59) & (2.84) & $(0.93)$ & $(-0.47)$ & $(-0.72)$ & (1.39) & $(0.75)$ \\
\hline \multirow{2}{*}{$\begin{array}{l}\text { Department } \\
\text { category of } \\
\text { the university }\end{array}$} & -0.2727 & -0.5000 & -0.2750 & -0.2500 & -0.2500 & 0.7143 & -0.6667 & $-1.0000 * \star$ & -0.6667 & -0.4444 & -0.3333 \\
\hline & $(-1.00)$ & $(-1.03)$ & $(-0.70)$ & $(-0.55)$ & $(-0.53)$ & (1.05) & $(-1.51)$ & $(-2.73)$ & $(-1.62)$ & $(-1.13)$ & $(0.61)$ \\
\hline \multirow{2}{*}{$\begin{array}{l}\text { Years from } \\
\text { graduation }\end{array}$} & -0.0909 & $-0.5000 *$ & -0.2350 & -0.1460 & -0.2500 & -0.1429 & $-0.5277^{\star}$ & $-0.6667 * \star$ & $-0.6667 * \star$ & -0.3333 & $-0.6667^{\star}$ \\
\hline & $(-0.68)$ & $(-2.12)$ & $(-1.44)$ & $(-1.13)$ & $(-1.08)$ & $(-0.43)$ & $(-2.32)$ & $(-3.74)$ & $(-3.33)$ & $(-1.74)$ & $(-2.50)$ \\
\hline \multirow[t]{2}{*}{ Hometown } & -0.4545 & -2.3600 & -0.2590 & 0.1667 & 0.2500 & -0.2857 & 0.5000 & -0.3860 & 0.6032 & -0.5556 & -1.6667 \\
\hline & $(-0.70)$ & $(-1.73)$ & $(-0.29)$ & (0.15) & $(0.22)$ & $(-0.18)$ & $(0.47)$ & $(-0.69)$ & $(0.75)$ & $(-0.59)$ & $(-1.28)$ \\
\hline \multirow{2}{*}{$\begin{array}{l}\text { Be } \\
\text { discriminated } \\
\text { or not }\end{array}$} & $-0.5455^{\star}$ & -0.5000 & -0.2500 & -0.6667 & -0.7500 & $-1.5714^{\star}$ & $-1.7500 * *$ & $-1.6667 * *$ & $-1.6667^{* *}$ & -0.5556 & $-1.6667^{\star \star}$ \\
\hline & $(-2.09)$ & $(-1.08)$ & $(-0.73)$ & $(-1.54)$ & $(-1.65)$ & $(-2.41)$ & $(-4.14)$ & $(-4.76)$ & $(-4.23)$ & $(-1.48)$ & $(-3.18)$ \\
\hline \multirow{2}{*}{$\begin{array}{l}\text { COVID-19 be } \\
\text { rebounding } \\
\text { again or not }\end{array}$} & $-0.5455^{\star \star}$ & $-0.7500 \star *$ & -0.3700 & -0.4167 & -0.1475 & -0.4286 & -0.4167 & -0.3333 & -0.3333 & $-0.4444^{*}$ & -0.3333 \\
\hline & $(-3.64)$ & $(-2.81)$ & $(-1.27)$ & $(-1.67)$ & $(-0.96)$ & $(-1.14)$ & $(-1.71)$ & $(-1.66)$ & $(-1.47)$ & $(-2.05)$ & $(-1.10)$ \\
\hline \multirow[t]{2}{*}{ Constant } & $4.9091^{* *}$ & $12.0000 * \star$ & $9.7500^{* \star}$ & 5.0000 & 5.0000 & 7.2857 & $9.3333^{\star \star}$ & $14.6667^{\star \star *}$ & 16.0000 ** & 4.7778 & 12.0000 ** \\
\hline & (2.82) & (3.87) & $(4.27)$ & (1.72) & $(1.65)$ & $(1.67)$ & (3.30) & $(6.27)$ & $(6.08)$ & (1.90) & (3.42) \\
\hline
\end{tabular}

Note.GAD-7 = 7-item General Anxiety Disorder Scale, PHQ-9 = 9-item Patient Health Questionnaire(depression), ISI-7 = 7-item Insomnia Severity Index Scale, IE: Impact of Event Scale-Revised(distress). ${ }^{\star \star} P<0.01 * P<0.05$.

\section{Discussion}

The results of the survey of 1,017 back-to-Wuhan college students indicated that the prevalence rates of anxiety, depression, insomnia, and distress were $44 \%$, $47.5 \%, 37.7 \%$, and $57.7 \%$, respectively, which were higher than those during the non-epidemic periods[21, 22]. It has been demonstrated that the increasing number of confirmed cases, suspected cases, the outbreak rebounded in other provinces or countries [30] and the continuous negative news reports about the COVID19 [31], have incited people to worry about the future trend of the epidemic, leading to people's anxiety, depression.

Previous studies have shown that the psychological health of college students under the influence of public health emergencies to a large extent, [15, 32, 33] on account of the college students' easier access to information related to the pandemic[34], lack of experience in responding to public health emergencies, and their studies and future career development affected by the COVID-2019 [21].

Meanwhile, the result manifested the prevalence rates of anxiety, insomnia, and distress were significant different on college students of different ages and educational level, deriving from the greater pressure of scientific research of the master's and doctoral students, longer home isolation time, worse scientific research environment, and lower efficiency. There were no system online psychological, academic, and employment guidance courses for college students. Similar studies have indicated that some household income might be affected, consequently, some students could concern sources for tuition due to the outbreak of the pandemic [35].

In accordance with the hypothesis, the quantile regression confirmed the degree of education level has a positive influence on depression. It reports that those suffering more from anxiety could worry about the negative influence of COVID-2019 on their academics and science research, indicating that the degree of education level is a sensitive indicator that affects the score of depression. The impact of years from graduation on insomnia and distress is negative, and the 
impact gradually becomes larger in the median and upper quantiles. The higher education level and the closer to graduation, the more anxiety, depression, insomnia, and distress the participants have. It might result from that limited ways of pressure release under closed management have affected the academic or employment development of college students near graduation.

Furthermore, it also classified and analyzed whether college students had ever been discriminated against due to the experience in Wuhan after returning to school, and the attitude on the future trend of COVID-2019. Due to experience related Wuhan city, some discrimination had also affected the mental health of college students to a certain extent, which is consistent with previous research results[36]. The results showed that there were differences in the level of mental health among college students with discrimination and worried about the rebound of the epidemic. It might be related to the stigmatization of Wuhan in the early stage of the epidemic[37]. At the same time, news of repeated fluctuations in the epidemic situation in Dalian, Beijing and other places would also affect the feeling of college students.

However, the gender on the prevalence rate was not significant difference, keeping with the previous research finding[20,38], which might be caused by the narrowing of the gap of people's access to education and information currently. But the majority of surveys conducted previously found the significant difference among the different gender, such as American male college students are easily depressed than female [39], on the contrary to Alansari's research in Saudi Arabia [40]. To be further confirmed, the traditional views of many emotional women under the peer pressure and high expectation from society and family, might increase the risk of depression.

Although telephone and online chat psychiatric treatment were advocated during the COVID-19 pandemic [41], the universities should also pay more attention to the mental health of back-to-Wuhan college students, especially in Wuhan. At present, the psychological counseling centers for college students are passive, and they should actively carry out psychological interventions for students near graduation to understand the reasons behind and help them get out of their difficulties. This research innovatively chooses to investigate the mental health of college students returning to school in Wuhan in the post-epidemic period and proposes key associated factors of mental health, which is conducive to maintain the mental health of college students and provide education and management.

The current study has several limitations. First, quantile regression could capture the heterogeneous associations between mental health and explanatory variables, however, the cross-sectional survey was hard to deduce causal inference and had a certain amount of information offset. A longitudinal study could be performed in the further study. Secondly, the research only studied the mental health of back-to-Wuhan college students, and did not cover other parts of China, such as Beijing, Guangzhou, etc., which rebounded in a small range in the post-epidemic period. Third, owing to the unavailable sampling framework and close-off management of back-to-Wuhan college students, convenient sampling was used to collect data, which could not represent the interest population and existed bias. The sample size is not sufficiently representative, which may have a certain impact on the results. Then, the mental health variables were measured by maturity scales, while, self-report instruments might respond bias.

\section{Conclusion}

In conclusion, the findings of this crossed-sectional study suggested that COVID-19 caused the relatively high prevalence rate of the back-to-Wuhan students on depression, anxiety, insomnia, and distress syndrome. The back-to-Wuhan students near graduation, being discriminated against owing to the experience in Wuhan city and worrying about the future trend of COVID-2019 were linked with a higher risk of developing depression and anxiety symptoms than others. These effects were stronger in the bottom and median quantile of anxiety and distress. Moreover, the long-term psychological effects covering causal inference and mediation analysis will help specify the impact of mental health in this population are worth further research.

\section{Abbreviations}

\section{COVID-19}

Coronavirus disease-2019; GAD-7:Generalized Anxiety Disorder Scale; PHQ-9:Patient Health Questionnaire-9; ISI-7:Insomnia Severity Index-7; IES-R:Revised Impact of Event Scale; SARS:Severe acute respiratory syndrome coronavirus; H1N1:Hemagglutinin type-1 Neuraminidase type-1 influenza virus.

\section{Declarations}

\section{Acknowledgments}

We sincerely thank the ethical approval of Tongji Medical College, Huazhong University of Science and Technology. Also, we would like to thank all participants in this study.

\section{Author's Contributions}

Q.W.: Participated in the conceptualization, investigation, formal analysis, manuscript writing and validation; L.Z. (Lijun Zhuo): Participated in the investigation, data curation and validation; H.L.: Participated in the investigation and data curation; L.Z. (Ling Zheng): Participated in the investigation and editing; G.M.: Participated in the investigation and editing; H.T.: Participated in project administration and funding acquisition. All authors have read and agreed to the published version of the manuscript.

\section{Funding}

This research received no external funding. 
Data Availability Statement

The data presented in this study are available on request from the corresponding author. The data are not publicly available due to privacy.

\section{Ethics approval and consent to participate}

The study was approved by the Ethics Committee of Tongji Medical College, Huazhong University of Science and Technology (protocol code IORG No: IORG0003571 and date of approval: 28 June 2020). And the informed consent was obtained from all subjects involved in the study. All methods were carried out in accordance with relevant guidelines and regulations.

\section{Consent for publication}

Not applicable.

\section{Conflicts of Interest}

All authors declare no conflicts of interest.

\section{Author details}

${ }^{1}$ School of medicine and health management, Tongji medical college, Huazhong university of science and technology, Wuhan 430030, China.

\section{References}

1. de Lima CVC, Candido EL, da Silva JA, Albuquerque LV, Soares LD, do Nascimento MM, de Oliveira SA, Neto MLR: Effects of quarantine on mental health of populations affected by Covid-19. J Affect Disord 2020, 275:253-254.

2. Li X, Lu P, Hu L, Huang T, Lu L: Factors Associated with Mental Health Results among Workers with Income Losses Exposed to COVID-19 in China. International Journal Of Environmental Research And Public Health 2020, 17(15).

3. Lu YC, Shu BC, Chang YY, Lung FW: The mental health of hospital workers dealing with severe acute respiratory syndrome. Psychotherapy And Psychosomatics 2006, 75(6):370-375.

4. Zhang Q, Huang XQ, He XB, Yang XL, Yu SY: Comparing high-risking SARS medical members' attitude and their mental health characters during the epidemic outbreak of SARS in Beijing. International Journal Of Psychology 2004, 39(5-6):453-453.

5. Park JS, Lee EH, Park NR, Choi YH: Mental Health of Nurses Working at a Government-designated Hospital During a MERS-CoV Outbreak: A Crosssectional Study. Archives Of Psychiatric Nursing 2018, 32(1):2-6.

6. Park HY, Park WB, Lee SH, Kim JL, Lee JJ, Lee H, Shin HS: Posttraumatic stress disorder and depression of survivors 12 months after the outbreak of Middle East respiratory syndrome in South Korea. Bmc Public Health 2020, 20(1).

7. Hall RCW, Hall RCW, Chapman MJ: The 1995 Kikwit Ebola outbreak: lessons hospitals and physicians can apply to future viral epidemics. General Hospital Psychiatry 2008, 30(5):446-452.

8. Maunder RG: Was SARS a mental health catastrophe? General Hospital Psychiatry 2009, 31(4):316-317.

9. Usher K, Bhullar N, Jackson D: Life in the pandemic: Social isolation and mental health. Journal Of Clinical Nursing 2020, 29(15-16):2756-2757.

10. Campion J, Javed A, Sartorius N, Marmot M: Addressing the public mental health challenge of COVID-19. Lancet Psychiatry 2020, 7(8):657-659.

11. Liu S, Yang L, Zhang C, Xiang Y-T, Liu Z, Hu S, Zhang B: Online mental health services in China during the COVID-19 outbreak. Lancet Psychiatry 2020, 7(4):E17-E18.

12. Chen Gui-mei RJ, He Xinran, Yuan Hongxu, Chen Ren, Wang Li, Xu Wangquan, Zheng Tao, Ding Hong Mental health status of medical staff based on SCL90 in Anhui Province during the epidemic situation of COVIDir/4区19. Chinese Journal Disease Control\&Prevention 2020, 24(8):(in Chinese).

13. Song Feifei WX, Ju Zhiying, Liu Aixiang, Liu Junjie, Wang Tao: Mental health status and related influencing factors during the epidemic of coronavirus disease 2019(COVID-19). HUBEI JOURNAL OF PREVENTIVE MEDICINE 2020, 31(2):(in Chinese).

14. Liu D, Baumeister RF, Veilleux JC, Chen C, Liu W, Yue Y, Zhang S: Risk factors associated with mental illness in hospital discharged patients infected with COVID-19 in Wuhan, China. Psychiatry research 2020, 292:113297-113297.

15. Yang Y, Li W, Zhang QG, Zhang L, Cheung T, Xiang YT: Mental health services for older adults in China during the COVID-19 outbreak. Lancet Psychiatry 2020, 7(4):E19-E19.

16. Main A, Zhou Q, Ma Y, Luecken LJ, Liu X: Relations of SARS-related stressors and coping to Chinese college students' psychological adjustment during the 2003 Beijing SARS epidemic. Journal of counseling psychology 2011, 58(3):410-423.

17. Gu J, Zhong Y, Hao Y, Zhou D, Tsui H, Hao C, Gao Q, Ling W, Lau JT: Preventive behaviors and mental distress in response to H1N1 among university students in Guangzhou, China. Asia-Pacific journal of public health 2015, 27(2):Np1867-1879.

18. Zhai Y, Du X: Mental health care for intemational Chinese students affected by the COVID-19 outbreak. Lancet Psychiatry 2020, 7(4):E22-E22.

19. Gewin V: INTO THE DIGITAL CLASSROOM Five tips for moving teaching online as COVID-19 takes hold. Nature 2020, 580(7802):295-296.

20. Cao W, Fang Z, Hou G, Han M, Xu X, Dong J, Zheng J: The psychological impact of the COVID-19 epidemic on college students in China. Psychiatry Research 2020, 287. 
21. Chang Jinghui YY, Wang Dong: Mental health status and its influencing factors among college students during the epidemic ofCOVID-19. Journal of Southern Medical University 2020, 40(2):(in Chinese).

22. Yang Xiulan JW, Xia Guo, Wang Jun, Yu Wanwan: Analysis of the influence of social hierarchy background on depression and anxiety among college students. Chinese Journal Disease Control\&Prevention 2015, 19(12):(in Chinese).

23. Ren FF, Guo RJ: Public Mental Health in Post-COVID-19 Era. Psychiatria Danubina 2020, 32(2):251-255.

24. Hwang M: The Effects of Post-traumatic Stress of College Students on Suicidal Behavior: The Mediating Effect and Gender Differences of Mental Health. The Journal of Humanities and Social science 2019, 10(6):1013-1028.

25. Lu Q: Basic Intervention on Stress induced by SARS Epidemic. Chinese Mental Health Journal 2003, 17(8):(in Chinese).

26. Auerbach RP, Mortier P, Bruffaerts R, Alonso J, Benjet C, Cuijpers P, Demyttenaere K, Ebert DD, Green JG, Hasking P et al: Mental disorder comorbidity and suicidal thoughts and behaviors in the World Health Organization World Mental Health Surveys International College Student initiative. International journal of methods in psychiatric research 2019, 28(2):e1752.

27. Spitzer RL, Kroenke K, Williams JBW, Loewe B: A brief measure for assessing generalized anxiety disorder - The GAD-7. Archives Of Internal Medicine 2006, 166(10):1092-1097.

28. Kroenke K, Spitzer RL, Williams JBW: The PHQ-9 - Validity of a brief depression severity measure. Journal Of General Internal Medicine 2001, 16(9):606613.

29. Lin C-Y, Cheng ASK, Nejati B, Imani V, Ulander M, Browall M, Griffiths MD, Brostrom A, Pakpour AH: A thorough psychometric comparison between Athens Insomnia Scale and Insomnia Severity Index among patients with advanced cancer. Journal Of Sleep Research 2020, 29(1).

30. Bao Y, Sun Y, Meng S, Shi J, Lu L: 2019-nCoV epidemic: address mental health care to empower society. Lancet 2020, 395(10224):E37-E38.

31. Ayittey FK, Ayittey MK, Chiwero NB, Kamasah JS, Dzuvor C: Economic impacts of Wuhan 2019-nCoV on China and the world. Journal Of Medical Virology 2020, 92(5):473-475

32. Sun Q-H, Su Y: Psychological crisis intervention for college students during novel coronavirus infection epidemic. Psychiatry Research $2020,289$.

33. Jiang Ruichen LA: Mental health status and its influencing factors of college students in Anhui Province during the coronavirus disease 2019 pandemic. Journal of Environmental and Occupational Medicine 2020, 37(9):(in Chinese).

34. Wu Yi HX, Qian Dongfu: Study on status of mental health among college students during COVID-19 epidemic. Chinese Journal of Health Education 2020, 36(8):(in Chinese).

35. Peng L, Zhang J, Li M, Li P, Zhang Y, Zuo X, Miao Y, Xu Y: Negative life events and mental health of Chinese medical students: The effect of resilience, personality and social support. Psychiatry Research 2012, 196(1):138-141.

36. Huang Yueqin DW, Liu Zhaorui et al: Psychosocial Aspects in Three Universities during SARS Epidemic in Beijing. Chinese Mental Health Journal 2003, 17(8):(in Chinese).

37. Bruns DP, Kraguljac NV, Bruns TR: COVID-19: Facts, Cultural Considerations, and Risk of Stigmatization. Journal Of Transcultural Nursing 2020, 31(4):326-332.

38. Zhang Y-L, Liang W, Chen Z-M, Zhang H-M, Zhang J-H, Weng X-Q, Yang S-C, Zhang L, Shen L-J, Zhang Y-L: Validity and reliability of Patient Health Questionnaire-9 and Patient Health Questionnaire-2 to screen for depression among college students in China. Asia-Pacific Psychiatry 2013, 5(4):268275.

39. Grant K, Marsh P, Syniar G, Williams M, Addlesperger E, Kinzler MH, Cowman S: Gender differences in rates of depression among undergraduates: measurement matters. Journal Of Adolescence 2002, 25(6):613-617.

40. Alansari BM: Gender differences in depression among undergraduates from seventeen Islamic countries. Social Behavior And Personality 2006, 34(6):729-738.

41. Xiang Y-T, Yang Y, Li W, Zhang L, Zhang Q, Cheung T, Ng CH: Timely mental health care for the 2019 novel coronavirus outbreak is urgently needed. Lancet Psychiatry 2020, 7(3):228-229. 